\title{
Editorial
}

\section{Los problemas en el ISSS}

Los problemas en el Instituto Salvadoreño del Seguro Social (ISSS) no son nuevos. Durante la década de los años ochenta, los sindicalistas de la institución dieron muestras, en circunstancias adversas, de su disposición para correr los mayores riesgos. En aquel entonces eran inocultables los motivos políticos que animaban a los dirigentes sindicales de la institución. Sin embargo, esos motivos políticos coexistían con intereses estrictamente laborales, los cuales eran, en definitiva, los que hacían que la mayoría de trabajadores del seguro social simpatizaran con e incluso apoyaran a los sindicalistas.

En esa época, era fácil para las autoridades gubernamentales desestimar las peticiones de los trabajadores, pues bastaba para ello con interpretarlas como parte de una conspiración de la izquierda armada para desestabilizar al país. Si las cosas eran así, no quedaba más respuesta que la coerción sobre quienes protestaban. Una vez finalizado el conflicto armado, los trabajadores pudieron deslindar con más claridad sus intereses políticos de sus intereses sindicales. En la nueva coyuntura, necesidades urgentes, antes ocultadas tanto por la fraseología revolucionaria como por la propaganda gubernamental, ocuparon un lugar prioritario - casi exclusivo - en las demandas del movimiento laboral en el seguro social.

Ha habido muchas protestas, exigencias y presiones de los trabajadores pero, por regla general, las respuestas de las autoridades se han quedado cortas, muchas veces incluso respecto de los compromisos adquiridos previamente. En una dinámica que a ratos ha adquirido tintes de mutua intransigencia, los ánimos de los trabajadores del seguro social se han ido caldeando hasta desembocar en una situación como la actual, en la cual parecen estar dispuestos a llegar hasta las últimas consecuencias con tal de hacerle cumplir al gobiemo de Francisco Flo- 
res compromisos adquiridos durante la administración presidencial anterior. Por su parte, la respuesta del gobierno se ha decantado peligrosamente hacia las medidas de fuerza para hacer frente a un problema que es de su competencia resolver por medios pacíficos. Muy a tono con esquemas de decisión política de los viejos tiempos, ha ordenado la militarización de los centros de salud con el fin de controlar y presionar a los sindicalistas. Ello, lejos de contribuir a resolver el problema, ha añadido un nuevo elemento de tensión en un ambiente ya de suyo marcado por el recelo entre las partes. Hasta el momento, las autoridades no han sido audaces ni creativas en la elaboración de una propuesta de solución al problema; una propuesta que sea consecuente tanto con los compromisos previamente asumidos como con las necesidades de los trabajadores.

El problema del seguro social es, pues, un problema entre el gobierno y los trabajadores de la institución. Es un problema que tiene su origen en la insatisfacción de estos últimos en relación con sus condiciones laborales. Sus peticiones y demandas son claras al respecto. Pero también los trabajadores del seguro social están molestos por el modo cómo el gobierno de Francisco Flores ha asumido los compromisos adquiridos por la administración presidencial anterior. Por último, están temerosos de las consecuencias que se puedan seguir para ellos y sus familias de la implementación de un proceso de privatización en el sector salud. Es responsabilidad del gobiemo hacerse cargo de esas preocupaciones y demandas; desatenderse de ellas, minimizarlas o, peor aún, responder agresivamente, con amenazas verbales o de hecho, sólo hará que ellas se prolonguen indefinidamente. Y esto último nos remite a un tercero en discordia: el público usuario de los servicios de salud que ofrece el ISSS.

Ciertamente, el problema en el ISSS es, primordialmente, un problema entre los trabajadores de la institución y las autoridades gubernamentales. De aquí que para resolverlo ambas partes deban mostrar la mejor disposición y la mayor flexibilidad. Pero no se trata sólo de un problema entre los trabajadores de la institución y las autoridades, sino de un problema entre los usuarios, el ISSS y el gobierno, con lo cual el asunto se vuelve más complejo por lo menos en dos sentidos: en las soluciones y en las interpretaciones. Al nivel de soluciones, una vez que se considera el impacto sobre los usuarios que padecen la suspensión de los servicios que ofrece el seguro social, se cae en la cuenta de que aquéllas tienen que encontrarse en un plazo no muy prolongado, pues de lo contrario se estaría poniendo en riesgo la salud y la vida de muchas personas. Es decir, una huelga en la principal institución de seguridad social del país tiene implicaciones totalmente distintas a una huelga que se suscite en una empresa o institución de otra naturaleza. De aquí que las soluciones que se planteen para resolver un conflicto como el del seguro social, tanto por el lado gubernamental como por el lado de los trabajadores, deben considerar seriamente el impacto de su prolongación sobre los usuarios. 
Al nivel de interpretaciones es donde más irrumpe el tema de los usuarios. La prensa escrita no ha escatimado esfuerzos por hacer ver - informar le llaman- lo mucho que sufren quienes no son atendidos prontamente por unos empleados negligentes. El gobierno no duda en hacer a los trabajadores del seguro social responsables por el daño a la salud de los salvadoreños que provocan sus acciones. El diputado de ARENA Norman Quijano afirma que su partido siempre ha abogado por la salud del pueblo salvadoreño. La Asociación Nacional de la Empresa Privada (ANEP) se pronuncia en defensa "de nuestros trabajadores", privados del derecho de salud que les asiste debido a los "intereses de unos pocos". En fin, todo un cúmulo de apreciaciones que, en conjunto, están dominadas por una misma lectura del problema: los trabajadores del seguro social anteponen sus intereses - pocos se preguntan con objetividad cuán legítimos son- a la salud de los salvadoreños. Conclusión: los trabajadores del seguro social son unos irresponsables que merecen nuestra condena más absoluta. ¿Y la responsabilidad del gobierno? Pareciera que en las interpretaciones que predominan sobre el problema del seguro social el gobierno es, por enésima vez, víctima de una conspiración desestabilizadora. 